\title{
Transnational Pacific Islander Americans and social work: Dancing to the beat of a different drum
}

\author{
Halaevalu F. Ofahengaue Vakalahi and Meripa Taiai Godinet (Eds.), 2014 \\ NASW Press, Washington DC \\ ISBN 0871014491, pp. 184, paperback, NZD34.99
}

This book offers an important resource for social workers, educators and social service agencies working with Pacific transnational communities in the United States of America (US). The book proudly and intentionally weaves in the rich indigenous heritage and identities of Pacific communities. Editors Vakalahi and Godinet have invited a number of authors from Pacific indigenous groups to speak from their own backgrounds, such as Chamorro, Chuukese and Yapese from Micronesian communities as well as Samoan, Tongan and Hawaiian Polynesian communities in the US.

The book draws together commonalities and unique differences between Pacific Island communities in the US, and fills a critical knowledge gap in this region. There is a need to build critical capacity and visibility for groups which are not well known or written about such as Chamorro, Chuuk and Yap communities. Their narratives offer refreshing insider narratives from indigenous communities. A particular focus is the transnational perspective of Pacific Island communities who have migrated from their indigenous homelands and are now living in the US, and who maintain indigenous ties to their homelands.

In order to work competently with any cultural community, it is important for social work practitioners to have cultural competency and to continually build their own skills and knowledges to work with other communities. Each chapter gives an historical, political, social and cultural context, focussing on key factors to be cognisant of within each indigenous culture. Stories of cultural communities migrating from their own homelands to the US are shared. Cultural identity, acculturation, assimilation and colonisation are common themes. The book demonstrates ideal ways that social workers and agencies can respond more culturally effectively with respective Pacific Island communities in the US.

Examples include chapters focussing on the experiences of the Chamorro indigenous peoples, highlighting the impact of colonisation on their people, language, land and culture. The chapters give powerful voice and insight for social work practitioners on ways of working. Reclaiming indigenous histories and recognising the impacts of colonisation are critical starting points to understanding the Chamorro people. The social work practice considerations for those working with Ulithian clients are invaluable we cannot assume all Micronesian cultures are homogenous as there is such a diversity amongst the languages, dialects, cultures and lifestyle. Social workers must be self-aware of the unique nuances and be willing to challenge their own assumptions and examine their own positions when working crossculturally with Pacific communities.

Each chapter offers a context to be mindful of when engaging Pacific communities. The final chapter affirms strengths and considerations for moving forward in approaching and engaging in social work practice with Pacific American families. In particular, the strengths 
of cultural indigenous and spiritual ways of healing, including through forgiveness processes such as ifoga or fakalelei are examined. Many of the narratives shared, of Pacific clients being exposed to culturally ignorant and culturally insensitive practices, are heart-warming, and yet also heartbreaking.

The book highlights the need and importance for us all to have a deeper understanding and awareness of different Pacific contexts and histories, colonisation and immigration when working with Pacific American families. The need to be sensitive, self-aware and non-judgemental is highlighted so as not to label all groups as "Pacific Islanders," and to recognise the challenge to increase our own cross-cultural awareness. These cultural indigenous practices, which are deeply embedded in Pacific cultures, offer a tension against western American social systems and social services, particularly in how to respond more effective cultural ways. By comparison, there are similar themes and issues (such as migration, acculturation) which are shared in Pacific communities in Aotearoa New Zealand and Australia, although the cultural nuances are context-specific to local regions.
One possibility for the book might have been to offer some discussion questions for consideration. This would be particularly useful for social work students and educators who would like to further their knowledge of transnational Pacific social work practices and challenges across the globe.

As social workers improve ways of working with other cultural groups, it is imperative to have an understanding of the historical, political, and cultural worldview, spirituality, rituals, practices, languages and context of Pacific communities. Important tensions are highlighted in maintaining indigenous identity against (or within) an American western context, particularly for many Pacific nations where the western form of social work is still foreign.

The book is highly recommended, and particularly useful for social workers, agencies, and social work educators interested in cross-cultural social work practice with Pacific communities in the US local context. It will also appeal to Micronesian communities and social work educators as a useful resource in the classroom and in social work practices. 